\title{
The challenges with Glässer's disease in technified pig production
}

\author{
Daniele A. Pereira ${ }^{a, d^{*}}$, Filipe A. Dalla Costa ${ }^{b, d}$, Lívia B. Ferronic ${ }^{c, d}$, Carolina N. Moraes ${ }^{\mathrm{e}}$, \\ Ruben P. Schocken-Iturrino ${ }^{\mathrm{c}}$, Luís G. Oliveira ${ }^{\mathrm{a}, \mathrm{d}}$
}

\begin{abstract}
The swine upper respiratory tract is early colonised by Haemophilus parasuis, a bacteria which causes Glässer's disease under favorable conditions. Glässer's disease is a septicemic infectious disease characterised by causing polyserositis. The prevention of Glässer disease still represents a big challenge for the production chain, since the mechanism of systemic infection in pigs and virulence factors that prevent phagocytosis are not yet well understood. Even in swine herds with high sanitary standard, it is the main cause of mortality that has led to productive and economic losses in the pig industry worldwide. Although the $H$. parasuis genome sequence has been completed already, diagnosis is still difficult due to the existence of non-virulent strains and the early colonisation of the upper respiratory tract of healthy swines. This review aims to provide up-to-date information about the etiology, epidemiology, pathogenesis, clinical signs, gross and microscopic lesions, diagnosis, treatment and control of Glässer's disease.

Key words: epidemiology, swine, virulence factors, vaccines.
\end{abstract}

RESUMEN. El tracto respiratorio superior del cerdo es colonizado inicialmente por Haemophilus parasuis, bacteria que en condiciones favorables causa la enfermedad de Glässer. La enfermedad de Glässer es una afección infecciosa que se caracteriza por el desarrollo de poliserositis septicémica. La prevención de esta enfermedad sigue siendo un problema en la producción porcina tecnificada, ya que los mecanismos de virulencia de este microorganismo y los factores sistémicos que impiden la fagocitosis no son bien conocidos. Inclusive en rebaños con un alto estándar de salud, $H$. parasuis es la principal causa de mortalidad, generando así pérdidas productivas y económicas en la industria porcina a nivel mundial. A pesar de que la secuencia del genoma de $H$. parasuis se ha completado recientemente, el diagnóstico aún se complica por la existencia de cepas no virulentas y la temprana colonización del tracto respiratorio superior de cerdos sanos. El objetivo de esta revisión es entregar información actualizada respecto de la etiología, epidemiología, patogénesis, signos clínicos, lesiones macroscópicas y microscópicas, diagnóstico, tratamiento y control de la enfermedad de Glässer.

Palabras clave: cerdos, epidemiología, vacunas, virulencia

\section{INTRODUCTION}

Glässer's disease is considered a major bacterial infection with worldwide distribution that has caused considerable economic losses even in high health status farms worldwide (Oliveira and Pijoan 2004). Haemophilus parasuis (H. parasuis) is the etiological agent of Glässer's disease in swine. This bacterium colonises healthy pigs and, under certain circumstances, some strains are able to invade the host and cause severe lesions. The initial acquisitions of $H$. parasuis occur right after piglet birth during direct contact of the nut with the piglet (Aragon et al 2012). Systemic invasion is characterised by fibrinous polyserositis inflammation, polyarthritis and fibrinous meningitis (Oliveira and Pijoan 2004, Moleres et al 2015), and cause significant losses to producer due to reduction in weight gain, increases in the use of drugs, dead animals, and carcass depreciation (Castilla 2012).

Accepted: 21.03.17.2017.

aDepartamento de Clínica e Cirurgia Veterinária, Universidade Estadual Paulista, Jaboticabal, Brazil.

${ }^{b}$ Departamento de Zootecnia, Universidade Estadual Paulista, Jaboticabal, Brazil.

'Departamento de Patologia Veterinária, Universidade Estadual Paulista, Jaboticabal, Brazil.

${ }^{\mathrm{d}}$ GESSui - Grupo de Estudos em Sanidade de Suínos, Jaboticabal, Brazil. eDepartamento de Reprodução Animal, Universidade Estadual Paulista, Botucatu, Brazil.

*Corresponding author: DA Pereira; daniele.araujop@gmail.com
Nowadays, the increase in the occurrence of Glässer's disease is being more associated to the current practices in animal production and with the emergence of immunosuppressive viruses (Aragon et al 2012). Usually, the diagnosis of $H$. parasuis-associated disease is done according to clinical signs, pathological findings and bacterial isolation. However, since it is a commensal in the respiratory tract of pigs and there are non-virulent strains, an inconclusive diagnosis is common which difficult its control and improvements in vaccination programs. Based on that, it is evident the importance of developing a standardised diagnostic technic to improve disease control (Castilla 2012).

More information is still needed to better understand the defense mechanisms of $H$. parasuis because involves the activation of several elements of the innate and acquired porcine immune system. The factors responsible for colonization and systemic infection are not enlightened, while prevention and control of Glasser's disease continues to be challenging. Therefore the objective of this review was to update the main characteristics about the etiology, epidemiology, pathogenesis, clinical signs, macroscopic and microscopic lesions, diagnosis, treatment and control of Glässer's disease.

\section{ETIOLOGY}

The $H$. parasuis is the causative agent of Glässer's disease decribed by Glässer in the exudate of pig with fibrinous polyserositis around 1910 (Aragon et al 2012, 
Castilla 2012). However, its isolation was performed for the first time by Schermer and Ehrlich in 1922 (Little 1970). This is a gram-negative bacterium, small, rodshaped, pleomorphic, nonhemolytic, non-motile and microaerophile of Haemophilus genus of Pasteurellaceae family (Castilla 2012).

There are seven members in the of family Pasteurellaceae dependent on the $\mathrm{V}$ factor (NAD - nicotinamide adenine dinucleotide) found in the upper respiratory tract of pigs: Actinobacillus pleuropneumoniae (App) - agent of porcine pleuropneumonia (PP); Haemophilus parasuis - agent of Glässer's disease; and Haemophilus taxon minor group, and taxons C, D, E and F (Dousse et al 2008).

The first causal agent identified was the $H$. suis, and then, the Haemophilus influenzae. Initially, the biochemical characterisation concluded that they were very similar due to the requirement of both growth factor $\mathrm{X}$ (iron porphyrin) and V (NAD; Lewis and Shope 1931). Thus, different classification of $H$. parasuis species was classified based on the nomenclature accepted to Haemophilus genus (Oliveira and Pijoan 2004).

Due to nutricius demands of $H$. parasuis its cultivation has been hampered, several media enriched with V-growth factor are used for the cultures making necessary the use of media supplemented with NAD (chocolate agar, Levinthal agar, PPLO agar supplemented with NAD). Another possibility is the use of agar of sheep blood with a groove of Staphylococcus aureus to obtain the factor V. In this case, the $H$. parasuis grows around Staphylococcus aureus in the phenomenon called sathelitism (Castilla 2012). The identification of species is based on morphological characteristics and biochemical tests such as urease production, indole, oxidase, capacity of reduce nitrate to nitrite, catalase, glucose fermenter, sucrose, fructose, galactose and mannose (Kielstein et al 2001, Oliveira 2007).

According to the currently worldwide accepted classification, only 15 serotypes of $H$. parasuis have been identified. However, due to the large amount of non-typable samples, there is a high probability of existence of serological varieties that are different from those already described (Howell et al 2013). The development of genotyping techniques such as MLST (Olvera et al 2006, Mullins et al 2013), 16S rRNA gene sequencing (Christensen et al 2004) and analysis of selected outer-membrane proteins (Mullins et al 2009) helps to better characterise the strains from $H$. parasuis.

\section{PRINCIPAL EPIDEMIOLOGICAL CHARACTERISTICS}

The identification of serovars has practical applications in local and global epidemiology such as the quantification of how many serovars are causing a single outbreak and discovering a link between particular strains with those found in others geographical points. There is not direct association between genotype and serovar. Isolates from the same serovar may include different strains, whereas strains with identical genotypes may differ regarding their serovars (Turni et al 2010). The severity of Glässer's disease is associated to the immune status of the herd. There is no certainty which factors are responsible for different degrees of virulence in this bacterium (Kielstein and Rapp-Gabrielson 1992).

Several studies to identify the prevalence profiles have been performed worldwide. The serovar 4 was identified as the dominant while serovar 5 was usually isolated to $H$. parasuis in most countries such as China (Li et al 2009), USA (Rapp-Gabrielson and Gabrielson 1992), Canada (Tadjine et al 2004), Brazil (Macêdo et al 2009), Spain (Rubies et al 1999), and Japan (Morikoshi et al 1990). The results differ to isolations in Australia (Blackall et al 1997, Rafiee and Blackall 2000) and Denmark (Angen et al 2004) with the prevalence of serovars 5 and 13.

Virulence factors of Pasteurellaceae strains that colonise the upper respiratory tract are the capsule, protein profiles of membrane protein, fimbriae and lipopolysaccharides (Ruiz et al 2001). Oliveira and Pijoan (2004) demonstrated the presence of a group of proteins with molecular weight between 36 and $38 \mathrm{kDa}$ in a study of 98 samples of $H$. parasuis. The authors also observed the presence of these proteins in $90.7 \%$ samples isolated from systemic sites while they were absent in $83.4 \%$ samples isolated from the upper respiratory tract of healthy animals.

The prevalence of $H$. parasuis has increased for worldwide. In Brazil, its prevalence has increased nearly $2 \%$ per year. However, since small farms do not have the financial resources to maintain efficient sanitary control, this prevalence might be higher than suggested (Teixeira et al 2011). To prevent the herd from dissemination and infection, even in small farms, some practices such as early weaning and segregated production are recommended. According to Bello-orti (2014) found some virulent strains in lung and a biofilm-like growth in nasal turbinates and trachea. Indeed, some virulent strains were detected in association with macrophages, neutrophils and inside pneumocyte-like cells, while non-virulent strains were not detected in lung.

Most of the epidemiological studies on $H$. parasuis were done using serotyping (Zhang et al 2012). The relationship between serotype and virulence is unclear, and the cross-protection between different serotypes and the same serotype is variable (Hill et al 2003). Serotyping does not provide a correct discrimination of isolates to epidemiological studies, mainly because $15-41 \%$ of the isolates are not typeable (Oliveira et al 2003). However, the development of new molecular methods have boosted epidemiological studies on $H$. parasuis (Oliveira and Pijoan 2004), due to the possibility of characterising the isolates, compare them to others genotypes, and carry out association of some DNA profiles to virulence profile (Oliveira et al 2003).

\section{UPDATE ABOUT THE PATHOGENESIS}

Bacterial pathogenesis is multifactorial, requiring multiple mechanisms to cause infection and produce the 
clinical signals. The pathogenesis factors include to invade the host, bacterial multiplication and damage to host tissue (Bouchet et al 2009). Comparisons in functional assays between virulent and non-virulent strains of $H$. parasuis allow the identification of several virulence mechanisms that help the bacterium colonise and initiate the infection by adhesion and invasion of epithelial cells (Frandoloso et al 2012). As other members of Pasteurellaceae family, $H$. parasuis can avoid phagocytosis, but the bacterial factors involved in the virulence are still unknown (Costa-hurtado et al 2013).

The infection of $H$. parasuis occurs by aerosols and suspended particles in the air (Barcellos et al 2008). Firstly, the agent colonises the mucosa of nasal cavity, and membranes such as synovial, meningeal and pulmonary parenchyma, which cause severe inflammatory injuries induced by the agent infection (Smart et al 1993). The most virulent strains of $H$. parasuis invade endothelial cells more efficiently than nasal strains and support the role of invasion in the virulence of this bacterium, however, invasion of endothelial cells is not completely required (Aragon et al 2010).

According to Bouchet et al (2009), the bacterial adhesion to epithelial cells induces apoptosis, and the release of cytokines that may be important events for colonization. Antigenic properties of $H$. parasuis have been studied by evaluating the immune response against phenotypic markers, the capsule, fimbriae and outer membrane proteins (OMP), lipopolysaccharides (LPS) and capsular polysaccharides which have been associated with the colonization of the respiratory tract (Biberstein 1990, Oliveira and Pijoan 2004). Interference of phagocytosis by $H$. parasuis virulent strains is likely associated with presence of capsule (Olvera et al 2009).

Another pathogenesis-related aspect are the oligopolissacarideos that follow similar patterns in virulent and non-virulent strains (Zucker et al 1996). The adherence on the surface of epithelial cells of host through fimbriae or adhesins factors is an important point for colonization and pathogenicity of several bacteria. When present in the blood flow, the lipopolysaccharide is considered a virulence factor, because it disseminates intravascular coagulation and thrombosis (Macinnes and Desrosiers 1999). The mechanism of growth and persistence in the host cells is also benefited by neuramidases that are associated to the production of sialic acids, neuraminidase activity could be detected, quantified and correlated with the nanH gene sequence in the set of $H$. parasuis strains under analysis, although this activity did not display an apparent correlation with virulence (Martínez-Moliner et al 2012).

According to Olvera et al (2009), different susceptibilities to phagocytosis were observed in strains of different clinical origins. Strains isolated from the nose of healthy pigs were easily phagocytosed by alveolar macrophages (AMP), while those isolated from systemic lesions were resistant to this interaction. A possible explanation to this was the presence of a separate capsule identified after interaction with AMP, which can represent a resistance factor.

According to Oliveira and Pijoan (2004), acute septicemia and disseminated intravascular coagulation are often observed in cases of $H$. parasuis infection. The Cytolethal distending toxin can be an important virulence factor of $H$. parasuis due to its characteristic regarding adhesion and invasion in host cells (Zhang et al 2012).

\section{METHODS FOR DETECTING THE SICK ANIMAL}

Usually, diagnosis of Glässer's disease at farm is done according to clinical signs, presence of lesions at necropsy, and bacteriologic culture (Vahle et al 1995). Clinical signs showed by infected pigs are highly variable and depend on immune status of herd, strain virulence and stage of infection (Santos et al 2012). Haemophilus parasuis causes Glässer's disease (fibrinous polyserositis), pneumonia and sudden death in pigs, but the bacterium can also be found in the upper respiratory tract of healthy piglets (RappGabrielson et al 2006).

At the beginning, pigs may show increased body temperature, apathy and inappetence, progressing to coughing, dyspnoea, body weight loss, lameness, incoordination, cyanosis, decubitus and death in some cases. In the acute form, sick pigs show abruptly anorexia, fever (temperature above $40{ }^{\circ} \mathrm{C}$ ), inappetence, cyanosis, and lethargy. Due to the tropism for membrane serosase depending on the site of occurrence of the injury, it can cause coughing, dyspnea, nasal discharge, abdominal breathing and claudication (Nedbalcova et al 2006). On the other hand, when the disease progress to chronic form, clinical signs such as chronic arthritis, adherence of serous, increased scrap animals with respiratory signs, hair creepy and opaque, or death may be observed (Santos et al 2012). Neurological clinical signs such as tremors, incoordination, paddling, convulsion and lateral position can be found in both forms (Macinnes and Desrosiers 1999, Nedbalcova 2006). Although it is not common, some animals may present swollen and cyanotic head as a result of acute myositis of the masseter muscle, where the subcutaneous fascia and fat become dilated with fibrin-purulent content (Hoefling 1991).

\section{MACROSCOPIC AND MICROSCOPIC LESIONS}

During post-mortem examination at farm characteristics as serofibrinous or fibrino-purulent exudate on mucosal surface and characteristics of pleuritis, pericarditis, peritonitis, meningitis, and polyarthritis are observed (Menin et al 2005). H. parasuis can cause three clinical forms of Glässer's diseases. The sporadic one occurs in young pigs due to stress factors and is known as the classic form of Glässer's disease. The lesions observed in the first form are fibrinous and purulent exudate on serosal surface (polyserositis) of synovium, pericardium, peritoneum, pleura and meninges (Menin et al 2005, Santos et al 2012). In 
the second one, certain characteristics such as septicemia without polyserositis, sub-capsular kidney bleeding and sudden death are found. In the third form, $H$. parasuis can cause pneumonia and be isolated as primary or secondary agent in infections of Circovirosis (PCV2) and virus from swine Reproductive and Respiratory Syndrome (PRRS) (Santos et al 2012).

The progress of $H$. parasuis infection is gradual. In pigs challenged by the respiratory route, signals as lethargic and high rectal temperature were found after $16 \mathrm{~h}$ post-inoculation. The first macroscopic lesions present in necropsy, were described by moderate amount of turbid liquid into the pleural, pericardial and peritoneal cavities. Pigs inspected after 36 hours post-infection showed fibrin clots in the pericardium, pleura, peritoneal fluid and joint and fibrin-purulent exudate into pericardial, pleural and peritoneal cavity found between 96 and 108 hours (Vahle et al 1995, Oliveira and Pijoan 2004).

According to Nedbalcova et al (2011) and Santos et al (2012), the necropsy of dead pigs infected by $H$. parasuis showed serofibrinous or fibrin purulent exudate on the surfaces of the peritoneum, pericardium, pleura and joints. Hyperemic liver, splenomegaly, catarrhal bronchopneumonia, acute and purulent hepatitis and encephalitis are commonly finding in infected pigs.

Microscopic lesions include inflammation of serous membrane with the presence of neutrophils and macrophages infiltrated (Menin et al 2005). Sometimes, $H$. parasuis infection may result in acute septicemia, cyanosis, subcutaneous and pulmonary edema, and death can occur without the typical serosal inflammation (Desrosiers et al 1986). Fasciitis and myositis (Hoefling 1991) and purulent rhinitis (Vahle et al 1995) have also been described.

\section{DIAGNOSIS}

Usually, diagnosis of Glässer's disease is based on clinical signs, presence of lesions at necropsy, and bacteriologic culture. As previously commented, isolation of $H$. parasuis depends on special needs, which can difficult the confirmation of this agent in the laboratory. Routinely, the identification is done using culture of clinical samples onto blood agar, NAD-supplemented media and chocolate agar. Some alternatives for diagnosis are the use of technics such as immunohistochemistry (Amano et al 1994, Segales et al 1997), oligonucleotide specific capture plate hybridization (Calsamiglia et al 1999), serological diagnosis (Oliveira and Pijoan 2004) and PCR (Oliveira et al 2001).

Serological diagnosis of $H$. parasuis is inconsistent and inaccurate. Nowadays, the development of molecular biology has been improving diagnosis techniques and providing new alternatives. The PCR has been far more sensitive and specific in $H$. parasuis detection than the other techniques (Oliveira et al 2001, Oliveira and Pijoan 2004) especially the sensitivity of the real-time PCR combined with high specificity makes it a very valuable tool for the diagnosis of Glässer's disease (Turni et al 2010).

The culture from clinical samples can be done from fibrin-purulent contents of the pericardium, pleura, peritoneum, joints and cerebrospinal fluid samples (Menin et al 2005). However, due to particular characteristics of $H$. parasuis, the bacterium isolation from clinical samples is difficult. A possible solution is the use of supplement media with antibiotics (bacitracin, lincomycin or crystal violet) to improve growth, isolation and recovery from contaminated samples. The growth is noted within 24-48 hours of incubation at $37{ }^{\circ} \mathrm{C}$ as a small, translucent and non-hemolytic colony (Nedbalcova et al 2006). Since samples may contain the agent in low quantity, pigs may have been medicated, or mistakes during collecting, handling and transporting of the sample may occur, negative results in bacterial culture do not discard the herd from H. parasuis (Oliveira and Pijoan 2004, Menin et al 2005).

The presence of $H$. parasuis as commensal of upper respiratory tract makes necessary not only isolation but also the identification of strains to determine its prevalence in herd (Menin et al 2005). Molecular methods give a better characterisation of isolates for analysis of profiles associated to virulence, and greater accuracy to monitor the distribution, prevalence and the emergence of new highly virulent isolates in swine herds (Macedo et al 2009). The use of molecular techniques as Enterobacterial Repetitive Intergenic Consensus (ERIC-PCR) allows the definition of prevalent strains that affects the herd (Oliveira and Pijoan 2004). The ERIC-PCR technic uses primers helps to detect different genotypes in isolates from the same serotype, which is important to understand better the epidemiology of the disease (Macedo et al 2009).

Systemic samples are indicated for bacterium isolation, while nasal and lung samples are not recommended. Genomic studies are elucidating problem of cross-immunity between strains, identifying virulent clones, and developing alternative methods of control. The differential diagnosis should be done for Streptococcus sp, Erysipelothrix rhusiopathia, Mycoplasma hyorhinis, Actinobacillus suis, Salmonella cholerasuis, Escherichia coli to conclude diagnosis of pigs with polyserositis in young pigs (Castilla 2012).

\section{HOW PREVENT PROBLEMS WITH $H$. parasuis IN PIG PRODUCTION}

Protection against $H$. parasuis depends on several factors of innate and acquired immune system, and serovar virulence. An effective prevention and control of $H$. parasuis have to be done according to an epidemiological study in each herd. The serotyping is an important tool to characterise strains and select the specific immunization to protect pigs. Vaccination of sows reduced not only the colonization of upper respiratory tract of piglets, but also the variability of strains of $H$. parasuis colonizing piglets (Cerdà-Cuéllar et al 2010). Sow-reared pigs are commonly 
protected against $H$. parasuis infection, whereas colostrum deprived piglets are susceptible to systemic infection (Oliveira and Pijoan 2004).

Usually, commercial (Riising 1981, Solano-Aguilar et al 1999, Baumann and Bilkei 2002, Bak and Riising 2002) or autogenous (Smart et al 1993, Mocellin et al 2010) vaccines are available to control and prevent $H$. parasuis infections. If commercial vaccines are not effective, the use of autogenous vaccines produced from clinical cases isolated from the own herd is recommended as an efficient alternative (Oliveira and Pijoan 2004), which has been mostly effective (Smart et al 1993). However, several studies have demonstrated that heterologous protection between different serotypes is restricted to specific serotypes, and the diversity in serovar existent has difficult the development of effective-cross protective immunity (Oliveira and Pijoan 2004).

The protocol of vaccine should receive special attention to achieve success in the immunization of herd. Because of the interference in the development of active immunity by vaccine, the period of application is an important issue. Reverse vaccinology and immunoproteomic analysis identified several putative virulence-associated genes and immunogenic proteins in different $H$. parasuis strains (Hong et al 2011). In order to avoid the development of clinical signs or lesions characteristic of systemic infection after be challenged, it is recommended to vaccinated at least sows. Some studies (Solano-Aguilar et al 1999; Baumann and Bilkei 2002) recommend the vaccination of gilts and piglets to prevent the development of clinical disease. Vaccinating gilts and piglets showed no or fewer macroscopic lesions than vaccinated piglets born from non-vaccinated gilts that had neurological and lameness signs (Solano-Aguilar et al 1999; Baumann and Bilkei 2002). Maternal immunity not only protects piglets against $H$. parasuis infection, but could also interfere with the response after vaccination. Maternally derived antibodies against Glässer's disease were above the positive level until thereabout three weeks of life in pigs, but an examination of the serological profile of the herd is powerfully recommended before immunization (Pomorska-mól et al 2011).

\section{RECOMMENDATIONS FOR TREATMENT}

Antimicrobials are normally used in the swine industry to treat and control Glasser's disease, but some antimicrobials have been shown to reduce colonization by $H$. parasuis, development of effective immune responses and immunomodulation (Macedo et al 2015). Because of the inefficacy of vaccination protocols, use of antimicrobials during livestock is necessary to treat $H$. parasuis infections. Usually, pigs treated early during infection are able to recover from the systemic damage. Therefore, treatment should start as soon as the first clinical signs appear.

Treatment using cephalosporins has been preconized instead of penicillin due concerns of resistance to drugs.
In laboratory, $H$. parasuis showed an increase of $40 \%$ in resistance to the use of tetracyclines (De la Fuente et al 2007). The protocols and dose recommendations vary from case to case (Nedbalcova et al 2006). Olvera et al (2007) monitored a swine herd during one year evaluating the susceptibility to antimicrobial and observed that all isolates were resistant to amoxicillin $(30 \mathrm{mg})$, sensitive to enrofloxacin $(10 \mathrm{mg})$, doxycycline $(80 \mathrm{mg})$, sulfa-trimethoprim $(5.2+240 \mathrm{mg})$, and tylosin $(150 \mathrm{mg})$. Although antibiotic treatment can be very effective at controlling $H$. parasuis infections, it may also interpose with the development of protective immune responses against $H$. parasuis (Macedo et al 2015). Even though many serovars are considered sensitive to most antibiotic cited, monitoring susceptibility patterns of the agent and the judicious use of antimicrobials to treat Glasser's disease are still important criteria to be considered before administration of therapy.

Antibiotic treatments and vaccination may be used to control infection caused by $H$. parasuis, but the permanent use of antibiotics may result in an increased cost of production and may create resistance to these antibiotics (Oliveira and Pijoan 2004).

\section{FINAL CONSIDERATIONS}

Glässer's disease has been a challenge for the swine production. Although $H$. parasuis usually emerged as a major cause of nursery mortality, the several factors involved in prevalence and control of infections remain unknown. Some stressful practices such as weaning, transportation, and numerous sites of production may have affect the epidemiology of $H$. parasuis within herds. A possibility to prevent and control $H$. parasuis is the use of uniform age to weaning, prevent segregation in different ages and decrease stressor agents that cause immunosuppression. The development of molecular techniques has improved identification of virulence factors, differentiated and genotyped strains, defined the true prevalence of systemic infection, and helped to better understand infection an diseases mechanisms. However, further studies are needed to better understand this agent and have an active control over the pig herd.

\section{REFERENCES}

Amano H, Shibata M, Kajio N, Morozumi T. 1994. Pathologic observations of pigs intranasally inoculated with serovar 1, 4 and 5 of Haemophilus parasuis using immunoperoxidase method. $J$ Vet Med Sci 56, 639-644.

Aragon V, Segales J, Oliveira S. 2012. Glässer's disease. In: Zimmerman JJ, Karriker LA, Ramirez A, Schwartz KJ, Stevenson GW. (ed). Diseases of Swine, $10^{\text {th }}$ ed. Wiley-Blackwell, Iowa, USA, Pp 760-769.

Argen $\varnothing$, Svensmark B, Mittal KR. 2004. Serological characterization of Danish Haemophilus parasuis isoaltes. Vet Microb 103, 255-258.

Bak H, Riising HJ. 2002. Protection of vaccinated pigs against experimental infections with homologous and heterologous Haemophilus parasuis. Vet Rec 151, 502-505. 
Barcellos DESN, Mores TJ, Santi M, Gheller NB. 2008. Avanços em programas de biosseguridade para a suinocultura. Acta Sci Vet 36, 33-46.

Baumann G, Bilkei G. 2002. Effect of vaccinating sows and their piglets on the development of Glasser's disease induced by a virulent strain of Haemophilus parasuis. Vet Rec 151, 18-21.

Bello-Orti B, Costa-Hurtado M, Martinez-Moliner V, Segalés J, Aragon V. 2014. Time course Haemophilus parasuis infection reveals pathological differences between virulent and non-virulent strains in the respiratory tract. Vet Microbiol 170, 430-437.

Biberstein EL. 1990. Our understanding of the Pasteurellaceae. Can J Vet Res 54, 78-82.

Bouchet B, Vanier G, Jacques M, Auger E, Gottschalk M, et al. 2009. Studies on the interactions of Haemophilus parasuis with porcine epithelial tracheal cells: Limited role of LOS in apoptosis and pro-inflammatory cytokine release. Microb Pathog 46, 108-113.

Calsamiglia M, Pijoan C, Solano G, Rapp-Gabrielson V. 1999. Development of an oligonucleotide-specific capture plate hybridization assay for detection of Haemophilus parasuis. J Vet Diagn Invest 11, 140-145.

Castilla KS, Gobbi DDS, Moreno LZ, Paixão R, Coutinho et al. 2012 Characterization of Haemophilus parasuis isolated from Brazilian swine through serotyping, AFLP and PFGE. Res Vet Sci 92, 266-371.

Cerdà-Cuéllar M, Naranjo JF, Verge A, Nofrarias M, Cortey M. 2010. Sow vaccination modulates the colonization of piglets by haemophilus influenza. Vet Microbiol 145, 315-320.

Christensen H, Kuhnert P, Olsen JE, Bisgaard M. 2004. Comparative phylogenies of the housekeeping genes $a t p D$, inf $B$ and $r p o B$ and the 16S rRNA gene within Pasteurellaceae. Int J Syst Evol Microb 54, 1601-1609.

Costa-Hurtado M, Aragon V. 2013. Advances in the quest for virulence factors of Haemophilus parasuis. Vet J 198, 571-576.

Costa-Hurtado M.; Olvera A, Martínez-Moliner V, Galofré-Milà N, Martínez P. 2013. Changes in macrophage phenotype after infection of pigs with Haemophilus parasuis strains with different levels of virulence. Infect Immun 81, 2327-2333.

De la Fuente AJ, Tucker AW, Navas J, Blanco M, Morris SJ, et al. 2007. Antimicrobial susceptibility patterns of Haemophilus parasuis from pigs in the United Kingdom and Spain. Vet Microbiol 120, 184-191.

Desrosiers R, Phaneuf JB, Broes A. 1986. An outbreak of atypical Glassers disease in Quebec. Proc Int Congr Pig Vet Soc 9, 277.

Dousse F, Thomann A, Brodard I, Korczark BM, Schlatter Y. 2008. Routine phenotypic identification of bacterial species of the family Pasteurellaceae isolated from animals. J Vet Diagn Invest 20, 716-724.

Frandoloso R, Martínez-Martínez S, Gutiérrez-Martin CB, Rodríguez-Ferri EF. 2012. Haemophilus parasuis serovar 5 Nagasaki strain adheres and invades PK-15 cells. Vet Microb 154, 347-352.

Hoefling DC. 1991. Acute myositis associated with Haemophilus parasuis in primary SPF sows. $J$ Vet Diagn Invest 3, 354-355.

Hong M, Ahn J, Yoo S, Hong J, Lee E, et al. 2011. Identification of novel immunogenic proteins in pathogenic Haemophilus parasuis based on genome sequence analysis. Vet Microbiol 148, 89-92.

Howell KJ, Weinert LA, Luan SL, Peters SE, Chaudhuri, et al. 2013. Gene content and diversity of the loci encoding biosynthesis of capsular polysaccharides of the 15 serovar reference strains of Haemophilus parasuis. J Bacteriol 195, 4264-4273.

Keilstein P, Wuthe HH, Angen Ø, Mutters R, Ahrens P. 2001. Phenotypic and gentic characterization of NAD-dependent Pasteurellaceae from the respiratory tract of pigs and their possible pathogenetic importance. Vet Microbiol 81, 243-255.

Kielstein P, Rapp-Gabrielson VJ. 1992. Designation of 15 serovars of Haemophilus parasuis based immunodifusion using heatstable antigen extracts. J Clin Microbiol 30, 862-865.

Lewis PA, Shope RE. 1931. Swine influenza. II. Haemophilic bacillus from the respiratory tract of infected swine. J Exp Med 54, 361-371.

Li J, Jiang P, Wang Y, Li Y, Chen W, et al. 2009. Genotyping of Haemophilus parasuis from diseased pigs in China and prevalence of two coexisting virus pathogens. Prev Vet Med 91, 274-279.

Little TWA. 1970. Haemophilus parasuis infection in pigs. Vet Rec 87, 399-402.
Macedo N, Rovira A, Torremorell M. 2015. Haemophilus parasuis: infection, immunity and enrofloxacin. Vet Res 46, 1-6.

Macedo NR, Oliveira SR, Lage AP, Gueres RMC. 2009. Epidemiología molecular de Haemophilus parasuis. Ciênc Rur 39, 2576-2582.

Macinnes JI, Desrosiers R. 1999. Agentes of the "Suis-ide Diseases" of swine: Actinobacillus suis, Haemophilus parasuis, and Streptococcus suis. Can J Vet Res 63, 83-89.

Martínez-Moliner V, Soler-Llorens P, Moleres J, Garmendia J, Aragon V. 2012. Distribution of genes involved in sialic acid utilization in strains of Haemophilus parasuis. Microbiol 158, 2117-2124.

Menin A, Gava D, Vaz E.K. 2005. Aspectos gerais sobre a infecção por Haemophilus parasuis em suínos - Revisão. Rev Ciên Agrovet 4, 148-156.

Moleres J, Santos-López A, Lázaro I, J Labairu, Prat C, et al. 2015. Characterization of Haemophilus parasuis isolated from healthy pigs at weaning reveals a novel small plasmid bearing blaROB-1 and conferring resistance to $\beta$-lactams. Appl Environ Microbiol 81, 3255-3267.

Mores N, Souza JCA, Nogueira RHG, 1984. Estudo experimental da pleuropneumonia suína causada por Haemophilus pleuropneumoniae (Hpp). Patogenicidade e evolução das lesões anátomo-patológicas. Arq Bras Med Vet Zootec 36, 679-693.

Morikoshi T, Kobayashi K, Kamino T, Owaki S, Hayashi et al.1990. Characterization of Haemophilus parasuis isolated in Japan. JPN J Vet Sci 52, 667-669.

Mullins MA, Register KB, Brunelle BW, Aragon V, Galofré- Mila et al. 2013. A curated public database for multilocus sequence typing (MLST) and analysis of Haemophilus parasuis based on an optimized typing scheme. Vet Microbiol 162, 899-906.

Mullins MA, Register KB, Bayles DO, Loving CL, Nicholson TL, et al. 2009. Characterization and comparative analysis of the genes encoding Haemophilus parasuis outer membrane proteins P2 and P5. J Bacteriol 191, 5988-6002.

Nedbalcova K, Kucerova Z, Krejci J, Tesarik R, Gopfert E, et al. 2011. Passive immunisation of post-weaned piglets using hyperimmune serum against experimental Haemophilus parasuis infection. Res Vet Sci 91, 225-229.

Nedbalcova K. Satran S, Jaglic, Z, Ondriasova R, Kucerova Z. 2006. Haemophilus parasuis and Glässer`s disease in pigs: a review. Vet Med 51, 168-179.

Oliveira S, Pijoan C. 2004. Haemophilus parasuis: new trends on diagnosis epidemiology and control. Vet Microbiol 99, 1-12.

Oliveira S, Galina L, Pijoan C. 2001. Development of a PCR test to diagnose Haemophilus parasuis infections. J Vet Diagn Invest 13, 495-501.

Oliveira S, Blackall PJ, Pijoan C. 2003. Characterization of the diversity of Haemophillus parasuis field isolates by use of serotyping and genotyping. American J Vet Research 64, 435-442.

Oliveira S. 2007. Haemophilus parasuis diagnostics. J Swine Health Prod 15, 99-103.

Olvera A, Ballester M, Nofrarias M, Sibila M, Aragon V. 2009. Differences in phagocytosis susceptibility in Haemophilus parasuis strains. Vet Res 40, 1-12.

Olvera A, Cerdà-Cuéllar M, Nofrorías M, Revilla E, Segalés J, et al. 2007. Dynamics of Haemophilus parasuis genotypes in a farm recovered from outbreak of Glässer`s disease. Vet Microbiol 123, 230-237.

Olvera A, Cerdà-Cuéllar M, Aragon V. 2006. Study of the population structure of Haemophilus parasuis by multilocus sequence typing. Microbiol 152, 3683-3690.

Pomorska-Mól M, Markowska-Daniel I, Rachubik J, Pejsak Z. 2011. Effect of maternal antibodies and pig age on the antibody response after vaccination against Glässers disease. Vet Res Commun 35, 337-343.

Rafiee M, Blackal PJ. 2000. Establishment, validation and use of the Kielstein-Rapp-Gabrielson serotyping scheme for Haemophilus parasuis. Aust Vet J 78, 172-174.

Rapp-Gabrielson VJ, Gabrielson DA. 1992. Prevalence of Haemophilus parasuis serovars among isolates from swine. Am J Vet Res 53, 951-956.

Riising HJ. 1981. Prevention of Glasser's disease through immunity to Haemophilus parasuis. Zbl Vet Med B 28, 630-638. 
Rubies X, Kielstein P, Costs LI, Riera P, Artigas C, et al.1999. Prevalence of Haemophilus parasuis serovars isolated in Spain from 1993 to 1997. Vet Microbiol 66, 245-248.

Ruiz A, Oliveira S, Torremorrel M, Pijoan C. 2001. Outer membrane proteins and DNA profiles instrains of Haemophilus parasuis recovered from systemic and respiratory sites. J Microbiol 39, 1757-1762.

Santos JL, Sobestiansky J, Santos LF. 2012. Doença de Glässer. In: Sobestiansky J (ed). Doenças dos Suínos. $1^{\text {st }}$ ed. Cânone Editorial, Goiânia, Brazil, Pp 135-140.

Segales J, Domingo M, Solano GI, Pijoan C. 1997. Immunohistochemical detection of Haemophilus parasuis serovar 5 in formalin-fixed, paraffin-embedded tissues of experimentally infected swine. $J$ Vet Diagn Invest 9, 237-243.

Smart NL, Hurnik D, Maciness JI. 1993. An investigation of enzootic Glässer's disease in a specific-pathogen-free grower-finisher facility using restriction endonuclease analysis. Can Vet J 34, 487-490.

Solano-Aguilar GI, Pijoan C, Rapp-Gabrielson V, Collins J, Carvalho LF, et al. 1999. Protective role of maternal antibodies against Haemophilus parasuis infection. Am J Vet Res 60, 81-87.

Tadjine M, Mittal KR, Bourdon S, Gottschalk M. 2004. Development of new serological test for serotyping Haemophilus parasuis isolates and determination of their prevalence in North America. J Clin Microbiol 42, 839-840.

Teixeira ML, Kuchiishi SS, Brandelli A. 2011. Isolation of Haemophillus parasuis from diagnostic samples in the south of Bazil. Braz J Vet Pathol 4, 122-125.

Turni C, Pyke M, Blackall PJ. 2010. Validation of a real-time PCR for Haemophilus parasuis. J Appl Microbiol 108, 1323-1331.

Vahle JL, Haynes JS, Andrews JJ. 1995. Experimental reproduction of Haemophilus parasuis infection in swine: clinical, bacteriologic, and morphologic findings. J Vet Diagn Invest 7, 476-480.

Xu Z, Yue M, Zhou R, Jin Q, Fan Y, et al. 2011. Genomic characterization of Haemophilus parasuis SH0165, a highly virulent strain of serovar 5 prevalent in China. PLOS ONE 6, e19631.

Zhang B, He Y, Xu C, Feng S, Liao M, et al. 2012. Cytolethal distending toxin (CDT) of the Haemophilus parasuis SC096 strain contributes to serum resistance and adherence to and invasion of PK-15 and PUVEC cells. Vet Microb 157, 237-242.

Zucker BA, Baghian A, Traux R. 1996. Detection of strain-specific antigenic epitopes on the lipooligosaccharide of Haemophilus parasuis by use of monoclonal and polyclonal antibodies. Am J Vet Res 57, 63-67. 
